\title{
Green Technology Implementation Model for Sustainability
}

\author{
Norjihan Abdul Ghani \\ Universiti Putra Malaysia, 43400 UPM Serdang, Selangor Darul Ehsan, Malaysia \\ Ghani778@hotmail.com
}

\author{
Article Info \\ Journal of Journal of Enterprise and Business Intelligence (http://anapub.co.ke/journals/jebi/jebi.html) \\ Doi: https://doi.org/10.53759/5181/JEBI202202003 \\ Received 15 June 2021; Revised form 10 August 2021; Accepted 05 October 2021. \\ Available online 05 January 2022. \\ (C2022 Published by AnaPub Publications.
}

\begin{abstract}
Studies on green technology implementation models are limited. This can be observed through an article search in almost all green technology journals related to transportation management in government agencies. Studies on green technology are widely carried out in private agencies, such as the industry and private businesses, but are less focused on in government agencies. The main objective of this study was to identify green technology implementation models, based on the previous concept papers. In this study, three models were identified and highlighted, namely the KAP Model, the Blueprint 2.0 Framework, and the Green Readiness Framework. This study was performed on the basis of developing a green technology model suitable for government agencies. Future research may focus on the development of a green technology implementation framework in the public sector in Malaysia.
\end{abstract}

Keywords- Green technology framework; Sustainability; Green Technology.

\section{INTRODUCTION}

Studies on green technology implementation models are limited. This can be seen through an article search in almost all green technology journals related to transportation management in government agencies. Studies on green technology are widely performed in private agencies, such as the industry and private businesses, but are less focused in government agencies. Table 1 shows two articles that mention green technology implemented in private agencies [1], and there is an article that mentioned green technology implemented in business [2].

Table 1. Green Technology Article List

\begin{tabular}{clll}
\hline Year & Journal & Article & Focus \\
\hline 2016 & Indian journal of & Application of green technology & Green technology for agriculture \\
& science and & in agriculture sector - a solution & \\
& technology & for sustainable food production &
\end{tabular}

$2015 \quad$ Journal of business and social entrepreneurship (GBSE)

Proceeding of PERKEM 10
Development of green skills competency model toward competency improvement of polytechnic lecturers in Malaysia

Potential of Islamic financing in national green technology industry
Green technology among polytechnic lecturers

Islamic financing in green technology industry 
2014

KANUN Journal

2013

American journal of
economics and
business
administration

Malaysian online journal of educational management (MOJEM)

International journal of business administration

American Journal of agriculture and forestry

Northwestern

journal of technology and intellectual property

2012 The American journal of tropical medicine and hygiene

Journal of environmental research and development

2011 Emerging greentechnology entrepreneurs : entrepreneurial pathways to growth in the hybrid and plug - in hybrid/ electric vehicle space

2010 Thesis
Environmental sustainability and green technology financing from the sharia law perspective

Embracing green technology innovation through strategic human resource management: a case of an automotive company

The barriers to adoption of green technology by higher education institutions in Malaysia

Consumers' acceptance towards green technology in automotive industries in Malacca, Malaysia

Climate change and green technology for enduring agriculture

The role of patent law in incentivizing green technology the role of patent law in incentivizing green technology

Green technology for a sustainable agriculture

Contribution of green technology in sustainable development of agriculture sector

ICSB world conference paperStockholm, Sweden
Green technology from the perspective of the law

Green technology Innovation in automotive company

Green technology by higher education institutions

Green technology in automotive industries

Green technology for agriculture

Patent law in incentivizing green technology

Green technology for agriculture

Green technology for agriculture

Green-Technology Entrepreneurs
Awareness level of green technology among northern region engineering technology teachers 
Furthermore, green technology framework is frequently implemented in other areas such as agriculture, education, and law, but less focused on transportation. There are four studies related to the implementation framework in agriculture [3] while there are three articles in education [4] and three articles in the law [5].

The transport sector has identified key issues, among which is related to carbon emissions, the second highest sector in Malaysia by $21 \%$, compared to other sectors such as industrial and manufacturing [6]. In Malaysia, there are many government agencies such as the Royal Malaysian Police (PDRM), the Malaysian Armed Forces (ATM), the Road Transport Department (JPJ), and the Fire and Rescue Department that use transportation vehicles, such as cars, vans, lorries, and others. Table 1 shows the number of vehicles in these departments.

Table 2. Total Transportation Vehicles used by Government Agencies

\begin{tabular}{|l|c|c|c|l|}
\hline \multicolumn{1}{|c|}{ Type of Departmental Transport } & Land & Sea & Air & \multicolumn{1}{c|}{ Source } \\
\hline Royal Malaysian Police & 23,578 & 252 & 23 & PDRM Report, 2017 \\
\hline Malaysian Armed Forces & 1,360 & 177 & 154 & Wikipedia, 2016 \\
\hline Road Transport Department & 931 & - & - & JPJ Report, 2016 \\
\hline Fire and Rescue Department & 2,993 & 639 & 7 & $\begin{array}{l}\text { Malaysian Fire and Rescue } \\
\text { Department, 2015 }\end{array}$ \\
\hline
\end{tabular}

Based on Table 2, PDRM is the department that uses the most vehicles $(23,578$ vehicles) as compared to other government departments, followed by Fire and Rescue Department that utilises land, sea, and air vehicles (3,639 vehicles), while the Malaysian Armed Forces vehicles uses 3,639 vehicles on land, sea, and in the air, and last but not least, the Road Transport Department employs 931 land-based vehicles only.

The main objective of this study was to identify green technology implementation models based on previous studies. Three green technology implementation models were identified from previous research work, and they are the KAP Model [7] Blueprint 2.0 Framework (no specified date), and Green Information Technology Readiness Framework (G-Readiness) [8]. Based on these models, a dedicated technology implementation model for government departments will be developed in future studies.

\section{GREEN TECHNOLOGY AND ITS DEFINITION}

Green technology is the development of various methods and strategies for generating products that are environmentally friendly. To reduce global warming, alternative heating and development of Green Technology products are produced [9]. The main objective of this technology is to achieve rapid development, including economic development, while maintaining the environment. Research studies in green technology has shown that greenhouse gases has caused climate change and global warming [10]. Green technology can assist in realising sustainable development while lessening the negative effects on the environment. The main parameters in green technology are to create economic viability, sustainability, and justice [11]. Green technology is the application of science to preserve the natural environmental resources for overcoming the negative effects [12]. Green technology is also a technology that has been developed and employed in a way that does not disrupt the natural environment; it is environmentally friendly, as well as nurtures natural resources. According to [13] green technology is a system with tools that is used to preserve natural environmental resources in order to reduce the effect of pollution stemming from human activities. From this, it can be summarised that green technology is a model system with tools that are environmentally friendly and does not disturb the natural sustainability.

\section{Green Technology Implementation Framework}

Framework development that is suitable for green practices and green technology implementation is sorely needed. Therefore, there is a fundamental need to understand the implementation process in the context of green practices and green technology application. [3] had stated seven main criteria in developing a solid framework for fulfilling the requirements of green practices and green technology implementation, which are as follows:

- Systematic and easy to understand.

- Simple and structured.

- Have clear links between each element or step that have been outlined.

- Appropriate in different contexts.

- Represents readiness for deployment.

- Answers questions of "how?" and not "what".

- Cannot be held accountable of reasonable cost and time. 
These criteria can be a guideline when constructing a green practice framework and green technology implementation [14].

This section presents the output of several research development process frameworks that were previously studied. In limiting the scope of this study, the focus is only on the framework that is related to the green technology implementation process.

\section{KAP Model}

In [16] introduced the Research Concept Framework using the Knowledge, Attitudes and Practices (KAP) Model, as shown in Figure 1. This model formulated with the aim of obtaining an actual illustration about the level of awareness related to green technology amongst Engineering Technology teachers in the Northern Region. This model illustrates the three main parts, namely the input, process, and output. The input portion of the study was represented by the respondents, the part of the process covered the knowledge, attitude, and practice of respondents, and subsequently the output obtained was the awareness of the teachers.

Firstly, knowledge is information stored in long-term memory that will be accessed when needed [17] while attitude is the tendency of an individual toward some matter, event, or thing. It describes feelings toward something. Attitude has three components namely thinking, emotion, and behaviour [18]. Attitude is defined as a psychological form described through the behaviour of individuals who demonstrate consistent response and assessment [19]. Meanwhile the dictionary defines a practice as something that is performed normally. However, this framework is observed holistically without explaining in detail about the types of green technology used.

\section{PDRM Blueprint Framework 2.0}

The Blueprint Framework 2.0 is the continuation after the end of the implementation of the Green Practices and Green Technology Application Blueprint in 2015. It was developed to further enhance the Go Green agenda where activities and targets have been set for five years from 2016 to 2020 [20]. Figure 2 explains the framework of Green Practices and Green Technology Application Blueprint that was built in Blueprint 2.0 for Green Practices and Green Technology Applications Blueprint 2016 - 2020. This framework explains the main focus areas devoted to achieving sustainable PDRM goals and prosperous society. There are five main focus areas namely:

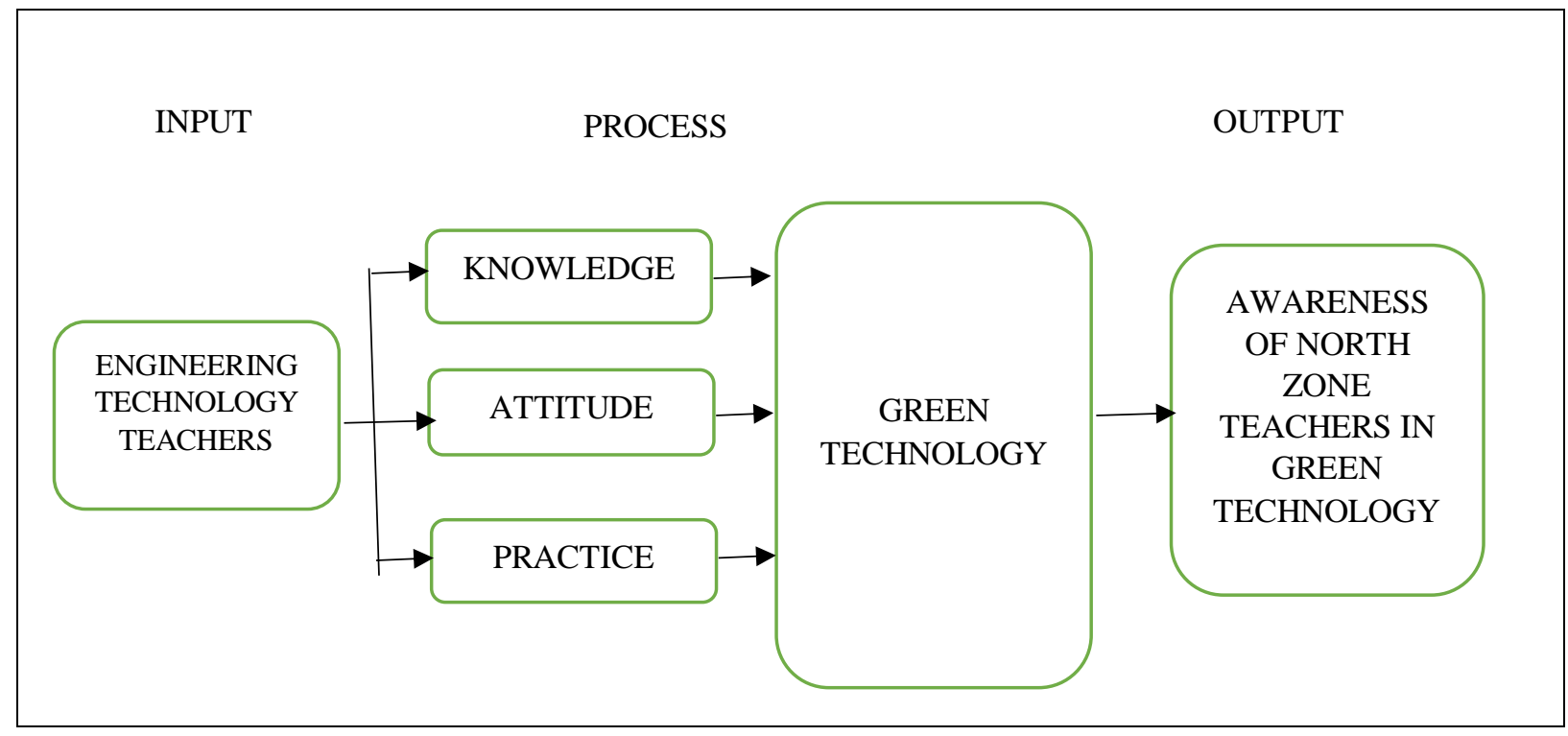

Fig 1. Research Concept Framework using the KAP Model [2]

- Daily management and Government Green Purchasing (GGP) practices: increase the level of awareness and competence of PDRM employees as well as enhancing the level of government green purchasing implementation.

- $\quad$ Building, energy, and utility: building management and maintenance in a systematic manner for improving the optimal usage and management of resources. 
- Transport management: regulate the rate of emission and pollution with a more efficient transport management as well as optimal resource management.

- Information and communication technology: upgrade equipment, software, and systems to reduce wastage, save on cost and more effective delivery.

- Waste management: manage waste more efficiently and orderly.

\begin{tabular}{|l|l|}
\hline Objectives & Agensi X lestari, masyarakat \\
sejahtera
\end{tabular}

Fig 2. Blueprint 2.0 Framework of Agency X (Source: Green Practices and Green Technology Implementation)

These key focus areas will enhance implementation of green practices and green technology applications in line with strategies and targets set under the 11th Malaysia Plan (RMK11). The benchmark in this framework is green activity and the implementation of green technology applications through government green procurement. However, although this framework describes the blueprint of green practices and green technology applications, it does not explain in detail how to implement the process.

\section{Green Information Technology Readiness Framework (G-Readiness)}

Green Information Technology Readiness Framework (G-Readiness) was constructed to assist organisations to evaluate their readiness to employ green information technology, as shown in Figure 3 that explains the Green Information Technology Readiness Framework (G-Readiness). In this framework, there are five important elements needed to realise the implementation of green information technology, which are (1) attitude, (2) policy, (3) practice, (4) technology, and (5) governance. G-Readiness represents the combination needed by the organisation to enable it to use environmental resources in a sustainable manner [15]. 
- Attitude is the effective and professional characteristics of leaders. It measures whether leaders are interested in economic, strategic, regulatory, environmental, and social issues related to the use of information technology.

- Readiness to the policy measures the extent of green and sustainable implementation in the organisation. Three value chain areas can be used to assess the extent of policy readiness, which are IT sourcing, IT operations and services, and end-of-life management. IT sourcing policy is the extent to which the organisation employs a purchasing policy that sets out green guidelines for the purchase of information technology equipment with minimal environmental impact. Meanwhile, IT operations and services is the extent to which services are provided by information technology infrastructure, such as PC power management, policy on staff use, and environmental policy. IT end-of-life management is the policy and regulation associated with the sale and completion of information technology equipment in the organization.

- Practices of an organisation is different from the aspect of policy implementation. Green information technology practices include the resource, operation, and management of information technology.

- Green information technology is associated with more environmentally friendly technology. The success of technology is to build green technology infrastructure. Among the green technologies that can be used include the recycling of information technology and the optimal energy power centre.

- Governance refers to the management of infrastructure to implement green information technology. It covers the governance of green technology and the environment.

This framework has the tendency toward explaining the required concepts in the preparation for implementing green information technology and it does not explain the type of green technology used.

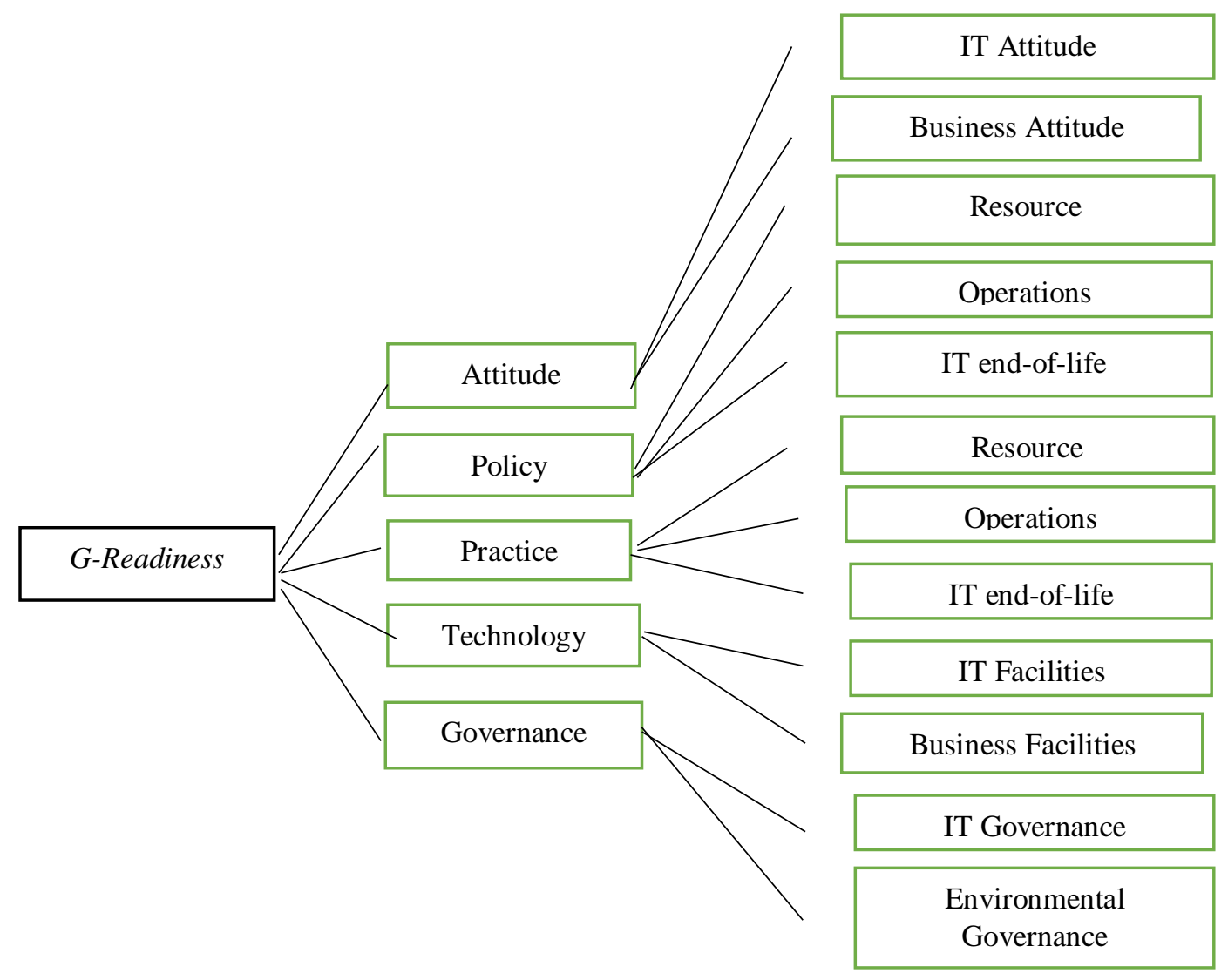

Fig 3. Green Information Technology Awareness Framework (G-Readiness) [15] 
The weaknesses in all three models have motivated this researcher to develop a more comprehensive and holistic implementation model so that it can become a guideline and reference for governmental agencies.

\section{CONCLUSION}

The KAP model was constructed for educators, specifically teachers in engineering technology, to instil the importance of green technology in the process of teaching and learning. Meanwhile, the Blueprint 2.0 model can be employed by officers, members, and civil servants in Agency X, and the G-Readiness model is for individuals/organisations that adopt green information technology concept. The weaknesses that can be observed in the KAP model is that even though it views the concept holistically, it fails to explain in detail about the components of green technology used. The weakness of Blueprint 2.0 model is that it does not explain in detail the method of implementation process, while the G-Readiness model has the tendency to explain the concepts that are required in the preparation to implement green technology and does not describe the focused green technology. Therefore, another model has been recommended based on Integration Definition for Process Modelling (IDEF0) because the pattern of this model contains the input, process, control, implementer, and output. This model is simple and easy to understand. This model can be effective in detailing out the system activities and can enable feedback to be given effectively. This model is expected to be more appropriate from the aspect of green technology development for governmental agencies.

\section{References}

[1]. G.-Y. Ning and D.-Q. Cao, "Improved Whale Optimization Algorithm for Solving Constrained Optimization Problems," Discrete Dynamics in Nature and Society, vol. 2021, pp. 1-13, Feb. 2021.

[2]. B. T. Warwick, I. Y. Kim, and C. K. Mechefske, "Multi-Objective Model Updating Optimization Considering Orthogonality," Journal of Computational and Nonlinear Dynamics, vol. 14, no. 6, Apr. 2019.

[3]. I. D. Rubtsova and D. A. Ovsyannikov, "Intense quasiperiodic beam dynamics in accelerating system: mathematical model and optimization method," Journal of Physics: Conference Series, vol. 941, p. 012092, Dec. 2017.

[4]. H. Adeli and H. Kim, "Cost optimization of composite floors using neural dynamics model," Communications in Numerical Methods in Engineering, vol. 17, no. 11, pp. 771-787, Oct. 2001.

[5]. A. O. Kravchenko, V. R. Kosach, K. A. Shkarina, I. O. Tykhonkova, and A. I. Khoruzhenko, "Optimization of in vitro model for analysis of tumor cell migration dynamics," Biopolymers and Cell, vol. 34, no. 6, pp. 476-486, Dec. 2018.

[6]. Z. Longqing, C. Guijuan, Z. Qian, and Z. Haiyang, "A Parameter Optimization Simulation Method for Crank Torque of Double Horse Head Pumping Unit Dynamics Model with Cable," Recent Patents on Engineering, vol. 12, no. 2, pp. 135-142, Jul. 2018.

[7]. S. I. Editor, "Simulation and Optimization of a System-Dynamics Model for Quality Control of a Closed-Loop Supply Chain," International Journal of Simulation: Systems, Science \& Technology, Jan. 2016.

[8]. M. Żuk, M. Syczewska, and C. Pezowicz, "Influence of Uncertainty in Selected Musculoskeletal Model Parameters on Muscle Forces Estimated in Inverse Dynamics-Based Static Optimization and Hybrid Approach," Journal of Biomechanical Engineering, vol. 140, no. 12 , Sep. 2018.

[9]. S. J. Hasaneini, C. J. B. Macnab, J. E. A. Bertram, and H. Leung, "The dynamic optimization approach to locomotion dynamics: human-like gaits from a minimally-constrained biped model," Advanced Robotics, vol. 27, no. 11, pp. 845-859, Aug. 2013.

[10]. Y. Jiang, "Dialectical Logic K-Model: Some Applications by Fuzzy-Probability Theory, Cause -Effect Analysis, Chaos Dynamics and Optimization Theory," Transactions on Machine Learning and Artificial Intelligence, vol. 6, no. 6, Dec. 2018.

[11]. S. Ma, L. Hou, W. Yao, and B. Lee, "A nonhomogeneous hidden Markov model of response dynamics and mailing optimization in direct marketing," European Journal of Operational Research, vol. 253, no. 2, pp. 514-523, Sep. 2016.

[12]. F. Marín Martínez, F. Campuzano Bolarin, H. Cañas Sánchez, And J. Mula Bru, "System Dynamics Model For Flow Time And Lot Sizes Optimization According To Quick Response Manufacturing (Qrm) Strategy,” Dyna, Vol. 96, No. 1, Pp. 105-111, Jan. 2021.

[13]. B. Li, X. Yang, and J. Yang, "In-Plane Flexible Ring Tire Model Parameter Identification: Optimization Algorithms," SAE International Journal of Vehicle Dynamics, Stability, and NVH, vol. 2, no. 1, pp. 71-87, May 2018.

[14]. J. Gao, P. Wu, T. Li, and A. Proctor, "Optimization-based model reference adaptive control for dynamic positioning of a fully actuated underwater vehicle," Nonlinear Dynamics, vol. 87, no. 4, pp. 2611-2623, Dec. 2016.

[15]. K. Wang and J. Xi, "Optimization of the driving waveform of a piezoelectric inkjet printhead based on a system dynamics model," Rapid Prototyping Journal, vol. 24, no. 8, pp. 1272-1280, Oct. 2018.

[16]. R. Seifried, "Optimization of the Internal Dynamics of Underactuated Robots," PAMM, vol. 9, no. 1, pp. 625-626, Dec. 2009. 